\title{
La Liga Comunista Espartaco: 1966-1972. Notas de investigación, indicios, tesis e interrogantes
}

The Spartacus Communist League: 1966-1972. Research notes, clues, theses and questions

José Rodrigo Moreno Elizondo*

Resumen: Este artículo brinda una interpretación de la práctica política de la Liga Comunista Espartaco (LCE) durante su existencia política. A partir del saber disperso y de fuentes de primera mano esbozo un balance preliminar, extraigo algunas conclusiones y señalo algunos caminos para desarrollar investigaciones futuras. Dicho organismo constituye un caso que muestra una arista de la reconfiguración de la conciencia global para la transformación revolucionaria de la sociedad en la década de 1960. Hacer la revolución en el propio país significaba no sólo construir un instrumento de conducción política sino enraizar en el tejido social, tarea a la que se arrojó la LCE con un gran desarrollo en el seno del movimiento estudiantil. La organización política sistematizó las experiencias existentes en ese sector social y las formas de lucha novedosas que emergieron, considerando la necesidad de recurrir a todas las formas de lucha -desde la vía electoral hasta el enfrentamiento armado-. El curso y desenlace del movimiento estudiantil-popular de 1968 le exigió plantearse el desarrollo de una política de masas en un periodo de agudización de la represión por parte del Estado. Pero no fueron las presiones externas las que acabaron con esta expresión política, sino las tensiones no zanjadas en el debate interno. Así, la LCE desapareció dejando tras de sí cuadros que se integraron a variados procesos sociales y políticos de las décadas posteriores.

Palabras clave: izquierda, México, articulación sociopolítica, organizaciones políticas

Abstract: This article provides an interpretation about the political practice of the Spartacus
Communist League (LCE, by its spanish acronym) during its political presence. From the
disperse knowledge about it and first hand sources I propose a preliminary balance, extract
some conclusions and point out several ways to develop future research. Such and organism
constitutes a case that shows an aspect of the reconfiguration of global consciousness about
revolutionary change of society in the decade of 1960. Making revolution in its own country
meant not only to build up a political direction instrument but also to root in social tissue, task
that the LCE directed with a great development among the student movement. The political
organization systematized the given experiences in this social segment and the new struggle
forms that emerged, considering the need of recurring to all forms of fight -from the electoral
way up to the armed confrontation-. The course and ending of the student-popular movement
of 1968 required it to consider the development of mass politics in a period of the sharpening
of repression coming from the State. But external pressures did not crush this political
expression, but tensions not solved in the internal discussion. Thus, the LCE faded living

* Mexicano. Maestro en Historia Moderna y Contemporánea por el Instituto de Investigaciones Dr. José María Luis Mora y doctorante en Ciencias Políticas y Sociales por la Universidad Nacional Autónoma de México. Correo electrónico: jrmorenoelizondo@gmail.com 
José Moreno, La Liga Comunista Espartaco: 1966-1972. Notas de investigación, indicios, tesis e interrogantes, Izquierdas, 49, julio 2020:1112-1133

behind political cadres that became part of several social and political processes in forthcoming decades.

Key words: left wing, Mexico, sociopolitical articulation, political organizations

Recibido: 27 enero 2019 Aceptado: 9 abril 2019

\section{Introducción}

La Liga Comunista Espartaco (LCE) es un referente político que permite comprender el devenir de la izquierda mexicana. Por una parte, debido a su crítica a los organismos partidarios precedentes -el Partido Comunista Mexicano (PCM), el Partido Obrero Campesino Mexicano (POCM) y el Partido Popular Socialista (PPS)-. Por la otra, al constituir una alternativa política durante la segunda mitad de la década de 1960. Intelectuales, académicos, escritores, dirigentes y trabajadores la moldearon y se formaron en sus filas, ${ }^{1}$ muchos de los cuales participan activamente en el bloque que gobierna México actualmente tras el triunfo electoral del Movimiento de Regeneración Nacional (MORENA) y su jefe político Andrés Manuel López Obrador (AMLO). No obstante, aún es incipiente nuestro conocimiento sobre dicho organismo.

Las primeras reflexiones se inscribieron en la autocrítica de ex militantes del espartaquismo. ${ }^{2}$ Implícitamente la LCE se incluía en la autocrítica del conjunto de las organizaciones espartaquistas de Arturo Anguiano publicada en 1969 en Nueva Praxis. ${ }^{3}$ Casi diez años más tarde Paulina Fernández analizó la LCE a partir de los posicionamientos políticos sobre carácter de la Revolución mexicana, del capitalismo, del Estado y de la nueva revolución. ${ }^{4}$ Años después, Fabio Barbosa le dedicó un espacio en la genealogía del espartaquismo y el desarrollo de otros organismos políticos tras su fractura. ${ }^{5}$ Es probable que debido al contexto de represión y persecución política del periodo, se señalasen pocos elementos respecto de la estructura, desarrollo orgánico y espacios de influencia, por los peligros que representaba para quienes habían militado en dicha organización.

Desde la década de 1990, la LCE fue recuperada por diversos estudios que la señalan por su relevancia para otras experiencias sociopolíticas. En 1993 Vivienne Bennet la identificó como matriz de la Organización Revolucionaria Compañero (ORC), impulsora de la Unión de Colonias Populares (UCP),

\footnotetext{
1 Armando Bartra, Paco Ignacio Taibo II, Carlos Pereyra, Carlos Monsiváis, Francisco Pérez Arce, Santiago I. Flores, Plutarco Emilio García Jiménez, Francisco Martín del Campo, Sigfrido Paz Paredes, Rubelio Fernández Dorado, Vicente Estrada Vega, Jorge Mesta, Rufino Perdomo, Adriana Corona, Enrique González Rojo, Antonio Martínez Torres, Amador Velasco Tobón, Carmelo Enríquez, Fabio Barbosa y Alberto Ulloa.

2 El espartaquismo, como corriente e identidad política, abrevó de la tesis de José Revueltas respecto de la inexistencia histórica del partido revolucionario del proletariado, la necesidad su construcción. Cfr. José Revueltas, Ensayo sobre un proletariado sin cabeza, México, Era, 1980 [1961].

3 Arturo Anguiano, "El espartaquismo en México. Aproximación crítica. Primera contribución a la autocrítica del movimiento revolucionario en México", México, 1968, en José Revueltas, un rebelde melancólico, México, Pensamiento Crítico, 2017, pp. 273-303; Anguiano, Entre el pasado y el futuro, p. 27.

${ }_{4}$ Paulina Fernández Christlieb, El espartaquismo en México, México, El Caballito, 1978.

${ }^{5}$ Fabio Barbosa, "Las utopías cambiantes", Nexos, $1^{\circ}$ de agosto de 1983, publicado un año más tarde como "La izquierda radical en México", Revista Mexicana de Sociología, México, Universidad Nacional Autónoma de México, vol. 46, núm. 2, abril-junio, 1984, pp. 111-138
} 
cofundadora de la Coordinadora Nacional del Movimiento Urbano Popular (CONAMUP) en 1982. ${ }^{6}$ Raúl Jardón logró identificar a algunos de sus militantes como delegados al Consejo Nacional de Huelga $(\mathrm{CNH})$ en 1968 y recuperó testimonios que dieron indicios de su participación en asambleas de base y en otros sectores sociales. ${ }^{7}$

La desclasificación de archivos de seguridad en 2002, la creación de la Fiscalía Especial para Movimientos Sociales y Políticos del Pasado (FEMOSOPP) y la publicación de un primer informe en 2006 sobre los crímenes cometidos por el Estado han brindado mayores pistas respecto a la represión ejercida sobre ex militantes. ${ }^{8}$ Entre otras cosas, la LCE ha sido referida como organización guerrillera, ${ }^{9}$ mencionada tangencialmente en relatos autobiográficos, estudios y semblanzas de ex militantes, ${ }^{10}$ como momento de tránsito hacia organizaciones maoístas de tipo único, ${ }^{11}$ por su relación con el movimiento estudiantil antes, durante y después de $1968,{ }^{12}$ así como matriz de organismos políticos. ${ }^{13}$

Existen visiones contrapuestas sobre su papel: desde su exiguo abordaje histórico en historias generales, ${ }^{14}$ pasando por la atribución de marginalidad, hasta la ponderación de su relevancia como polo

${ }^{6}$ Vivienne Bennet, "Orígenes del Movimiento Urbano Popular Mexicano: pensamiento político y organizaciones políticas clandestinas, 1960-1980”, en Revista Mexicana de Sociología, México, Universidad Nacional Autónoma de México, vol. 55, núm. 3, julio-septiembre, 1993, pp. 89-102.

${ }^{7}$ Raúl Jardón, 1968. El fuego de la esperanza, México, Siglo XXI, 1998. La lista de integrantes del CNH se corrigió y amplió en Raúl Jardón, El espionaje contra el movimiento estudiantil. Los documentos de la Dirección Federal de Seguridad y las agencias de inteligencia estadounidense en 1968, México, Ítaca, 2003.

${ }^{8}$ Dicho informe da cuenta de la detención-desaparición de Pedro Gorgonio Santiago, del encarcelamiento de Alberto Ulloa Borneman, Vicente Estrada Vega en Lecumberri y de Teresa Franco en la cárcel de mujeres de Santa Marta, considerados parte de la LCE en 1974, cuando dicho organismo había desaparecido. FEMOSOPP, Informe histórico a la sociedad mexicana, México, 2006, p. 674-675.

9 Octavio Rodríguez Araujo, "Violencia social (un intento conceptual para el México actual), Este país. Tendencias y opiniones, núm. 76, julio, 1997, p. 4.

${ }^{10}$ Camacho y Schmidt, op. cit.; Hernández, op. cit.; Alberto Ulloa Borneman, Surviving Mexico's Dirty War. A political prisioner's memoir, Philadelphia, Temple University Press, 2007; René Torres-Ruiz, "Carlos Pereyra: una breve mirada a su vida y obra", Estudios políticos, novena época, Núm. 23, mayo-agosto, 2011, pp. 197-214; José Manuel Vacah, "Taibo II, de alfabetizador de obreros en Ecatepec a director del FCE", Tercera vía, 10 de octubre de 2018; "El origen espartaquista de Taibo II y Armando Bartra, la herencia de José Revueltas", El Revueltas Times, 28 de octubre de 2018.

11 Xochitl Leyva y Christopher Gunderson, “The Tapestry of Neo-Zapatismo. Origins and Development", in Jai Sen and Peter Waterman (eds.), The Movements of Movements: Struggles for Other Worlds, New Delhi, OpenWord, 2011; Rodríguez, La izquierda en México, pp. 31-40.

12 J. Rodrigo Moreno Elizondo, "El movimiento estudiantil-popular de 1968 y la recomposición de las organizaciones políticas de izquierda", Revista Mexicana de Ciencias Politicas y Sociales, México, UNAM, Nueva Época, Año LXIII, núm. 234, septiembrediciembre, 2018, pp. 239-264; Fernando Herrera Calderón, "Working class-heroes: Barrio Consciousness, Studen Power and the Mexican Dirty War", en Jaime M. Pensado y Enrique Ochoa (ed.), México beyond 1968. Revolutionaries, radicals and repression during the global sixties and subversive seventies, United States of America, The University of Arizona Press, 2018, p. 160; Verónica Oikión Solano, "Student Organizing in Post-1968 Mexico City: The Coordinating Comision of Commitees of Struggle and State Violence", en Jaime M. Pensado y Enrique Ochoa, op. cit., p. 237; Florencia Ruiz Mendoza, "El Movimiento Estudiantil de 1968 en el proceso de radicalización hacia la lucha armada en México: 1968-1971”, Conflicto Social, Año 4, núm. 5, junio, 2011, pp. 355373; René Rivas Ontiveros, La iqquierda estudiantil en la UNAM. Organizaciones, movilizaciones y liderazgos (1958-1972), México, Universidad Nacional Autónoma de México-Facultad de Estudios Superiores Aragón/ Miguel Ángel Porrúa, 2007, pp. 172-174, 188-274, 278-288.

13 Es el caso de la Seccional Ho Chi Minh. Núñez, op. cit.

14 El clásico de Barry Carr soslaya a la LCE y su influencia política. La izquierda mexicana a través del siglo XX, México, Era, 1996; y tampoco se menciona en Max Ortega y Ana Alicia Solís, La izquierda mexicana. Una historia inacabada, México, Ítaca, 2012; en otras se señala apenas: Arturo Anguiano, Entre el pasado y el futuro. La izquierda en México, 1969-1995, México, Universidad Autónoma Metropolitana-Xochimilco, 1997, pp. 26-27; Octavio Rodríguez Araujo, La iqquierda en México, México, Orfila, 2015, pp. 31-40. Tampoco se hace mención de ella en el reciente balance historiográfico de Verónica Oikión, Eduardo Rey Tristán y Martín López Ávalos, El estudio de las luchas revolucionarias en América Latina (1959-1996). Estado de la cuestión, México, El Colegio de Michoacán, 2013. 
político. ${ }^{15}$ Ello ha llevado a considerarlo desarticulado respecto de la clase trabajadora, los movimientos sociales y sus reivindicaciones, por lo cual se ha soslayado su participación en procesos o coyunturas. ${ }^{16}$ También existe poca claridad respecto de su proceso de disolución, lo que ha llevado a considerar su transformación en organizaciones maoístas de tipo único. ${ }^{17}$ De ahí, la necesidad de un balance preliminar que nos permita comenzar a comprender con mayor profundidad dicho organismo político.

Para comprender mejor a la LCE he incorporado nuevas fuentes al saber existente. El informe de la FEMOSOPP en 2006 no consideró el conjunto de materiales depositados del Archivo General de la Nación (AGN) sobre dicho organismo pues se interesaba en documentar la represión por parte del Estado. Aquí se analizan documentos del AGN y el acervo de organizaciones armadas de México en la Mandeville Special Collections Library, perteneciente a la Universidad de San Diego California, Estados Unidos, publicados en la base de datos "Movimientos Armados en México", auspiciada por el Colegio de México. ${ }^{18} \mathrm{El}$ texto se nutre de testimonios recuperados en un proceso de investigación mayor que incluye uno de los organismos a que dio lugar la LCE al disolverse. ${ }^{19}$

Abordo la práctica política de la LCE bajo la inquietud de comprender su proceso de articulación sociopolítica. La pregunta por la articulación cuestiona la constitución de sujetos-actores sociopolíticos como comunidades consensuales y las mediaciones del ejercicio empírico de poder bajo una perspectiva estratégica. Dicha construcción no se reduce a la agregación discursiva de reivindicaciones -formal-, sino que tiene una dimensión material y orgánica al seno de la sociedad civil y la sociedad política -clases, actores sociales, movimientos, partidos políticos- ${ }^{20}$ En función de ello analizó la práctica política de la LCE, así como sus posicionamientos políticos, discurso, interpretación de la realidad, producción teórica y programática, las identidades y representaciones subjetivas en relación con la comprensión de su desarrollo orgánico, articulación social, iniciativas políticas, coyunturas y determinaciones estructurales.

Entre 1966 y 1972 la LCE asumió la construcción del instrumento de conducción política para la revolución en México. Buscó disputar dicha conducción social y política al PCM y otros partidos de la época en ámbitos tales como la solidaridad antiimperialista, en el tránsito de la consciencia global hacia lo local, ${ }^{21}$ en diversos sectores y regiones del país. La evidencia muestra que tuvo su mayor influencia en el sector estudiantil, donde sistematizó experiencias y formas de lucha novedosas que derivaron en iniciativas políticas como las preparatorias populares, durante su existencia, tanto como los autogobiernos y cogobiernos al poco tiempo de disolverse.

Es innegable que la represión del Estado incidió en la modelación de sus métodos y formas orgánicas e incluso en la captura de algunos de sus militantes. Pero su desaparición estuvo primordialmente ligada a tensiones internas derivadas del proceso de unidad, catalizadas por la

\footnotetext{
15 Para Luis Hernández Navarro fue "la organización maoísta más importante de finales de la década de 1960". "Antonio Martínez, el camarada Tomás”, La Jornada, México, 13 de julio de 2010.

16 Es el caso del movimiento estudiantil-popular de 1968. Cfr. Hugo Núñez Membrillo, Las organizaciones maoístas de los setentas y su vinculación con las luchas populares: el caso de la Seccional Ho Chi Minh, México, Universidad Nacional Autónoma de México, tesis de licenciatura, 2012; Aurora Camacho de Schmidt y Arturo Schmidt, "Translating the Fear. A Mexican Narrative of Militancy, Horror and Redemption", en Alberto Ulloa Borneman, Surviving Mexico's Dirty War. A political prisioner's memoir, Philadelphia, Temple University Press, 2007, pp. 1-17.

17 Rodríguez, op. cit., pp. 31-40.

18 Disponible en línea en http://movimientosarmados.colmex.mx/

${ }_{19}$ Dicho organismo es la ORC, analizado en el estudio comparativo de la investigación doctoral bajo el título "Poder Popular, organizaciones políticas y movimientos sociales urbanos antisistémicos: la Organización Revolucionaria Compañero y el Movimiento de Izquierda Revolucionaria, 1968-1989", en el programa de Doctorado en Ciencias Políticas y Sociales de la UNAM.

20 Sobre la cuestión de la articulación ver Isabel Rauber, América Latina. Movimientos sociales y representación politica, Buenos Aires, Pasado y Presente XXI, 2003, pp.52-53; Enrique Dussel, Política de la liberación. Vol. II. La arquitectónica, Barcelona, Trotta, 2009, p. 242.

21 A propósito de esta veta de indagación conocida como "sesenta globales", ver los ensayos en Christiansen, Samantha y Zachary A. Scarlett, The Third World in the global 1960's, New York, Berghahn Books, 2013.
} 
experiencia del movimiento estudiantil-popular de 1968, la autocrítica respecto a sus vínculos sociales orgánicos y su rol de conducción política. La pluralidad de organismos en que derivó mostró el abanico de tendencias que coexistía en su interior. Este panorama general se expone en los tres apartados que dividen a este artículo. No está de más señalar que esta interpretación no tiene pretensiones de exhaustividad, sino de constituir un esfuerzo preliminar a manera planteamiento indiciario.

\section{Del antiimperialismo y solidaridad en la periferia a la revolución local}

La LCE fue el resultado de un proceso de unidad enmarcado por dos acontecimientos fundamentales. En el ámbito local por el asalto al cuartel Madera, Chihuahua, por parte del Grupo Popular Guerrillero (GPG) el 23 de septiembre de 1965, como primer esfuerzo de lucha frente al Estado mexicano. En el ámbito latinoamericano por la Primera Conferencia Tricontinental de enero de 1966, en la Habana, Cuba. En el proceso confluyeron la Liga Comunista por la Construcción del Partido Revolucionario del Proletariado (LCCPRP) -dirigida por Carlos Pereyra-, la Unión Reivindicadora Obrero-Campesina (UROC) -dirigida por Rubelio Fernández Dorado-, al que finalmente se unió en 1966 la Liga Leninista Espartaco (LLE) -ya sin el fundador José Revueltas-.22 Todas eran producto de la de fragmentación del último quinquenio desde la creación de la LLE, aun cuando compartían la tesis central: la inexistencia del PCM como "cabeza del proletariado", la necesidad de construir el partido y desempeñar el papel de dirección política.

Desde 1965 el núcleo promotor del proceso unitario impulsó un acercamiento con el PCM que no fructificó. ${ }^{23}$ En la agenda de discusión se reafirmaron las discrepancias respecto a la tesis de la inexistencia histórica del partido de la clase obrera que el PCM se arrogaba -tampoco reconocido por los organismos espartaquistas en el POCM y el PPS-, la caracterización de la Revolución mexicana, las tareas a desarrollar entre obreros y campesinos, la caracterización el Estado mexicano y la perspectiva internacional. ${ }^{24}$ Los acuerdos en estos rubros, junto con las tesis políticas sobre sectores sociales como el obrero y el estudiantil consolidaron la fusión. En agosto de 1966 surgió la LCE dando continuidad a El Militante -publicación de la LCCPRP-, orientada a construir la herramienta de conducción política para el proceso revolucionario y la constitución de la independencia ideológica y política del proletariado bajo el horizonte socialista.

Las experiencias que conformaron a la LCE datan fines de los cincuenta. Por una parte, los movimientos magisterial y camionero de 1958, así como las protestas y movimientos estudiantiles en las universidades y los centros de formación magisterial en la década de 1960, donde el ex Comité del DF del PCM tenía influencia, luego como LCCPRP. Por otro, incorporó las vertientes que confluían en la UROC: los remanentes del movimiento en torno al campesino Rubén Jaramillo y el Partido Agrario Obrero Morelense (PAOM); parte del Movimiento Revolucionario del Magisterio (MRM); y el Movimiento Sindical Independiente (MSI) que participaba en el Frente Obrero Comunista de México (FOCM) dirigido por Juan Ortega Arenas. A ello se sumó la formación teórica y política de la célula Carlos Marx expulsada del PCM que originó la LLE. Las posiciones que los unificaron versaban sobre los sectores en que tendrían inserción inicial con caracterizaciones, tesis de los estudiantes y para el sector obrero, así como actividades conjuntas, bajo una perspectiva internacionalista, antiimperialista y de solidaridad con los procesos revolucionarios de la periferia del sistema-mundo capitalista. ${ }^{25}$

22 Sobre la historia de esos organismos ver Fernández, op. cit.; Núñez, op. cit., pp. 41-61; José Revueltas, Escritos políticos, t. III, Obras Completas, t. 14, Ediciones Era, México, 1984.

${ }^{23} \mathrm{La}$ LCE publicó un suplemento dedicado a las discrepancias. Respuesta al Partido Comunista Mexicano. Contra el revisionismo en México, suplemento de El Militante, Año 1, núm. 2, septiembre de 1966.

${ }_{24}$ Para esos posicionamientos remito al análisis de Fernández, op. cit.

${ }^{25}$ Liga Comunista por la Construcción del Partido Revolucionario del Proletariado, Unión Reivindicadora Obrero-Campesina, Declaración Conjunta. Derrota de la política oportunista de Ortega Arenas, México, 2a ed., 1966 [1965]; Liga Comunista por la 
De hecho, durante el primer lustro de los sesenta los organismos que confluyeron en la LCE se formaron primordialmente en actividades de solidaridad internacional en tensión con el PCM. Tras la expulsión de la célula Carlos Marx y una vez escindida la corriente crítica dentro del PCM en el Comité del Distrito Federal se desarrolló un proceso de disputa política en frentes políticos donde convergían. Entre ellos el Movimiento de Liberación Nacional (MLN) o las reuniones políticas que buscaban enfrentar la crisis de los misiles en 1962 en las que participaban junto con el PPS, el POCM, FOCM y el MLN. También los militantes de organizaciones espartaquistas se enfrentaron con las Juventudes Comunistas (JCM) en los actos de solidaridad con República Dominicana el 25 de abril de 1965.

Eso no desapareció con la formación de la LCE, incluso se agudizó tras el fracaso del proceso de acercamiento. Las tensiones continuaron luego de la Primera Conferencia Tricontinental y la creación de la Organización de Solidaridad con los Pueblos de Asia, África y América Latina (OSPAAAL) en enero de 1966. ${ }^{26}$ En evento con motivo de dicha conferencia se confrontaron con las JCM a propósito de la distribución de ElMilitante en el mitin de clausura del acto de solidaridad con Vietnam en el Teatro Esperanza Iris de la capital. Se llegó a un enfrentamiento abierto el 30 de junio de 1966 cuando se realizó un mitin antiimperialista y de defensa de la Revolución cubana en el auditorio Justo Sierra de la Universidad Nacional Autónoma de México (UNAM). El evento fue convocado por grupos estudiantiles y organizaciones políticas, entre ellas la LCE y sus militantes, un dirigente del MLN y el diputado Rafael Estrada Villa. Tras el presídium se habían instalado banderas de la LCE, la JCM y el Partido Mexicano de los Trabajadores (PMT). El PCM, la JCM y agrupaciones trotskistas agredieron verbal y físicamente a la LCE. Se desató una refriega que precipitó el fin del evento y se tradujo en descalificaciones ulteriores entre los organismos y sus expresiones estudiantiles.

Como resultado, el Comité Central de la LCE envió una carta a su homólogo del PCM en la que reprobaba dichos actos por su carácter sectario y por favorecer a la burguesía promoviendo la división. Aunque lo último expresaba claramente la segmentación de la izquierda en dos grandes polos, frente a la agresión imperialista la LCE manifestaba su disposición de resolver las discrepancias por medio de la discusión política y trabajo en espacios comunes. De ahí que manifestara disposición para construir un Frente Antiimperialista, llevando de manera conjunta la discusión política y "a participar en toda acción conjunta, bilateral o multilateral que se acuerde con el objetivo común de la denuncia del imperialismo y la defensa de la Revolución Cubana, y en general de todos los pueblos agredidos, con la condición de que tales acuerdos desemboquen necesariamente en acciones prácticas concretas". ${ }^{27}$ Así, la LCE participó en la movilización del 26 de julio en conmemoración de un aniversario del proceso cubano, pero denunció la falta de participación del PCM en el evento y los intentos de capitalizarlo políticamente. Por otro lado, buscó dotarla de contenido nuevo promoviendo la idea de vincular la lucha antiimperialista con el combate al capitalismo y la burguesía en el propio país. ${ }^{28}$

La relación de la LCE con el PCM en la lucha antiimperialista no prosperó y la construcción del frente tomó otro rumbo. Por informes de un agente de la DFS infiltrado en el Partido Obrero

Construcción del Partido Revolucionario del Proletariado, Unión Reivindicadora Obrero-Campesina, Liga Leninista Espartaco, Reforma o Revolución universitaria, $2^{a}$ ed., México, 15 de abril de 1966 [1964]; La Comisión Política del Comité Central de la Liga Comunista Espartaco al Comité Central del Partido Comunista Mexicano, 3 de julio de 1966, p. 3 en AGN/ DIPS/ caja 822, exp. s/n; "Nace la Liga Comunista Espartaco. Se unen tres organizaciones marxistas-leninistas", El Militante, Año 1, núm. 2, septiembre, 1966 , pp. 2-4; FEMOSOPP, op. cit., pp. 436; Núñez, op. cit., pp. 41-80.

${ }^{26}$ Este organismo fue creado para denunciar y divulgar las luchas de la periferia -el denominado Tercer Mundo-. Al respecto ver Ulises Estrada y Luis Suárez (ed.), Rebelión Tricontinental. Las voces de los condenados de la tierra de África, Asia y América Latina, Ediciones Tricontinental/ Ocean Sur, 2006.

27 La Comisión Política del Comité Central de la Liga Comunista Espartaco al Comité Central del Partido Comunista Mexicano, 3 de julio de 1966. AGN/ DIPS/ c. 822, e. s/n; “Actividades de la Liga Comunista Espartaco”, El Militante, Año 1, núm. 2, septiembre, 1966, p. 21.

${ }_{28}$ Comité Central de la Liga Comunista Espartaco, "Carta a la revista Política. La manifestación del 26 de Julio", 20 de agosto de 1966, en El Militante, Año 1, núm. 2, septiembre, 1966, p. 22. 
Revolucionario (trotskista) de México (POR-t), quien rendía informes detallados a Fernando Gutiérrez Barrios, sabemos que la LCE participó en reuniones preparatorias para conformar un frente antiimperialista. Dichos encuentros fueron convocados por la IV Internacional que seguía el programa de 1936 del Partido Obrero de Unificación Marxista (PUOM) de origen español, bajo la dirección de un delegado europeo y dirigente de la sección peruana. El objetivo era construir un polo revolucionario a fin de apoyar la lucha armada en el Cono sur, articulando México y Centroamérica, luego de la detención del grupo del POR-t vinculado con el M-13 Guatemalteco en abril de 1966. ${ }^{29}$

A la reunión asistieron diversas expresiones políticas de la izquierda local. Eran ex militantes POR-t, entre los que se encontraba el espía, representantes Partido Bolchevique de México (PBM), de la Liga Obrero Marxista (LOM), ex militantes del Frente Electoral del Pueblo (FEP), del extinto Movimiento Revolucionario del Pueblo (MRP) y de la LCE. En la ocasión dos representantes del Movimiento de Izquierda Revolucionaria (MIR) de Colombia y Venezuela plantearon la necesidad de fortalecer la lucha guerrillera informando de la unión de sus respectivos países con la guerrilla peruana y probablemente con la brasileña. El frente en México buscaba generar un polo clandestino articulado con Guatemala, Costa Rica y Nicaragua y se veía posible dada la tolerancia gubernamental y la simpatía con regímenes populares en Centroamérica. En la ocasión Tania Kovalchuk adelantó la posición de la LCE en términos la imposibilidad de apoyar el proceso, señalando que constituía una distracción para los revolucionarios mexicanos que debían enfocarse en lo local, posición que se corroboró en octubre por medio de Sandra Arenal (María). Dicho frente continuó organizándose con el resto de los cuadros participantes. ${ }^{30}$

Ello no significó que la LCE abandonase su práctica política antiimperialista. En diciembre de 1966 se pronunció a propósito de la reunión entre Gustavo Díaz Ordaz y Lyndon Johnson, presidente estadounidense, denunciando la persecución y represión a las luchas de liberación nacional. Evidenciaba que dicho encuentro trataba de ocultar la supeditación de México a los Estados Unidos. Al mismo tiempo señalaba la agresión de los imperialistas norteamericanos a Vietnam. ${ }^{31}$ Denunciaba dicha subordinación y propugnaba por la construcción partidaria. La lucha antiimperialista dio paso a la búsqueda de articulación sectorial, bajo el planteamiento de que la mejor manera de contribuir a la revolución internacional era hacerla en lo local. ${ }^{32}$ Para entonces la LCE desarrollaba una política interpelada por la situación doméstica, bajo la consideración de la necesidad de hacer la revolución en el propio país como contribución al proceso global. ${ }^{33}$

\footnotetext{
${ }^{29}$ Los detenidos fueron Adolfo Gilly, Óscar Fernández Bruno, Teresa Confretta de Fernández, Roberto Iriarte y Francisco Colmenares César. J. Posadas, "Sobre la detención de camaradas en México y de Adolfo Gilly", Boletín interno, Partido Obrero Revolucionario (trotskista), IV Internacional, 29 de junio 1966. En AGN/ DIPS, caja 2966-A, e. s/n; "Campaña mundial por la libertad de los trotskistas presos en México", Boletín de información del POR (trotskista), sección mexicana de la IV Internacional. AGN/ DIPS, c. 1576-A, e. 4. Adolfo Gilly, "Lo que existe no puede ser verdad”, New Left Review, núm. 64, julio-agosto, 2010, pp. 37-38.

30 Informe a Fernando Gutiérrez Barrios, 15 de septiembre de 1966; Informe a Fernando Gutiérrez Barrios, 21 de septiembre de 1966; Informe a Fernando Gutiérrez Barrios, 24 de septiembre de 1966; Informe a Fernando Gutiérrez Barrios, 30 de septiembre de 1966; Informe a Fernando Gutiérrez Barrios, 10 de octubre de 1966; Informe a Fernando Gutiérrez Barrios, 12 de octubre de 1966; Informe a Fernando Gutiérrez Barrios, 16 de octubre de 1966. AGN/ DIPS, c. 2966 e. s/n.

31 Comisión Política del Comité Central de la Liga Comunista Espartaco, "Qué pretende la burguesía y el imperialismo norteamericano con la reunión de los dos farsantes de la democracia”, México, D.F., 2 de diciembre de 1966, en AGN/ DIPS, C. 822 e. s/n.

32 Ello no significó abandonar posicionamientos al respecto, presentes en diversos textos de El Militante. Por ejemplo, en ese mismo año publicó un suplemento especial en el que asumió las tesis internacionalistas planteadas a fines de 1962 y principios de 1963 por el ex Comité del Distrito Federal del PCM, en los que se afirmó el respaldo a la revolución china. "Discrepancias en el movimiento comunista internacional", en suplemento de El Militante, Año 1, núm. 3, diciembre, 1966.

33 Rafael Castillo, "Luchar contra el imperialismo norteamericano es luchar contra el capitalismo en el propio país", en suplemento de El Militante, Año 1, núm. 3, diciembre, 1966, pp. 5-8.
} 
Frente al desarrollo del capitalismo en México, la agudización de la lucha de clases, la represión del Estado y los crecientes procesos masas, se planteaba un periodo de lucha democrática con un contenido de clase que la orientaba hacia una democracia popular, proletaria y anticapitalista. La LCE concluía de su análisis que el capitalismo dependiente del imperialismo de los Estados Unidos de Norteamérica, con la subordinación de la burguesía local, enfilaba a la agudización de la situación económica, de modo paralelo a la pérdida de algún atisbo de contenido popular en el Estado y, por el contrario, su defensa de los intereses de la burguesía. En tensión se encontraba al ascenso de las luchas populares pues tan sólo en 1966 se habían sucedido: la huelga universitaria, las luchas de normalistas; procesos populares y campesinos en Baja California, Sinaloa, Chihuahua, Nuevo León, Durango, Michoacán, Guerrero, Yucatán; las tensiones al seno de la Confederación Nacional Campesina (CNC) y la crisis del PPS; las manifestaciones antiimperialistas en apoyo a Vietnam y Cuba; finalmente, la represión a los trotskistas del Port ( $t$ ) y al MRP. Los rasgos de la nueva situación se sintetizaban así: una gran burguesía en el poder más agresiva, polarización política de las clases, agudización de las contradicciones en la burguesía, crisis de los mecanismos de control popular por parte del gobierno, así como el enfilamiento a una crisis nacional y el incipiente incremento del enfrentamiento de masas.

De ahí se derivaban varias conclusiones tácticas de la acción política. La imposibilidad de alianza con la burguesía para alcanzar la democracia. La necesidad extender las herramientas legales lo más posible, evitar la represión y la disolución de las organizaciones de los trabajadores y revolucionarios evitando que fueran reducidas a la clandestinidad. La urgencia de construir un partido revolucionario del proletariado independiente de la burguesía y de sus partidos políticos. Aprovechar las contradicciones coyunturales entre segmentos de la burguesía garantizando la independencia ideológica y política. Impulsar la organización independiente de obreros y campesinos. Finalmente, ante la intensa inquietud política en el país y la crisis política nacional que se anunciaba entre camioneros o estudiantes, pero con posibilidades de recomposición para la burguesía, se planteaba pasar de la agitación y labor educativa a la vinculación más estrecha con las luchas populares para la acción política independiente. ${ }^{34}$

A partir de entonces, en casi seis años, la LCE impulsó trabajo político local y pasó de unas cuantas células a un primer proceso de diferenciación. Su primera estructura se asentó en las células Ricardo Flores Magón, Plutarco Galicia Jiménez, Praxedis G. Guerrero, Mártires de Río Blanco y Comuna de París. Para 1971 contaba con seccionales que estructuraban el trabajo sectorial: 28 de Marzo para los ferrocarrileros, Magisterial, Estudiantil, la Norte del Valle de México y la Ho Chi Minh. No sobra decir que en tal periodo la LCE experimentó la profundización de la represión por parte del Estado contra la izquierda y los movimientos sociales, la cual llegó hasta la eliminación sistemática y selectiva. ${ }^{35}$ No podemos negar que las presiones externas incidieron en su desarrollo interno e incidencia política. Ello nos permite ponderar los alcances y limitaciones de la vinculación en diversos sectores y sus iniciativas políticas, en las que buscó articular las luchas reivindicativas y políticas.

\section{El proceso de articulación orgánica: estudiantes, obreros, elecciones y lucha armada}

Aunque la organización inició trabajo de articulación con las demandas de diversos sectores sociales tuvo un crecimiento de modo particular en el estudiantil. Los organismos que se disolvieron en la LCE habían participado en el proceso de creación de la Central Nacional de Estudiantes Democráticos (CNED) en 1963, así como en los foros de discusión que sistematizaron experiencias y debates. En la II Conferencia Nacional de Estudiantes Democráticos realizada en 1964, la célula Julio Antonio Mella del entonces

34 "Panorama de la lucha de clases en México. Los nuevos rasgos de la situación nacional", El Militante, Año 1, núm. 3, diciembre, 1966, pp. 1-6. A desarrollar los aspectos de la situación nacional se dedica el número.

35 Roberto González Villarreal, Historia de la desaparición. Nacimiento de una tecnología represiva, México, Terracota, 2012. 
Partido Revolucionario del Proletariado (PRP) -luego LCCPRP-, planteaba una crítica a la política de las JCM en las universidades. Se criticaba la tesis del supuesto carácter apolítico del estudiante, ponderando, por el contrario, su papel político en diversos procesos históricos, ligado a las causas populares. Se planteaba que los eventos recientes habían demostrado la articulación de la lucha por la reestructuración de la educación superior con la de la participación política en las luchas populares, reconociendo en sus reivindicaciones una huella eminentemente política. Dicha condición dotaba al estudiante de un carácter revolucionario en tanto garantizaba su independencia ideológica.

Tales conclusiones derivaban del análisis de su situación en las últimas décadas. Por un lado, la elitización de la universidad, la restricción de la matrícula y su reorientación bajo los intereses industrializadores de una burguesía cada vez más reaccionaria. Por otro, el fortalecimiento de las luchas estudiantiles desde 1940 y particularmente desde su participación en los movimientos sociales de 1958. De ahí que a partir de 1959 surgieran numerosos esfuerzos por construir un instrumento de conducción política: experiencias como el Consejo Nacional Estudiantil en el movimiento de la Escuela Nacional de Maestros (1960) que dio lugar al Bloque Estudiantil Revolucionario como coordinación para impulsar actos de solidaridad con Cuba y la sección IX del magisterio, así como el Primer Congreso Nacional por la Liberación de los Presos Políticos. Luego de ello se experimentó un reflujo que llevó a los estudiantes, bajo la influencia del PCM y la cooptación de los organismos estudiantiles, a una lógica petitoria frente a las autoridades universitarias. Por ello se consideraba necesario explicitar el contenido de clase de la educación e impulsar la organización estudiantil independiente. De ahí que no bastara con promover una reforma universitaria que diera continuidad a los preceptos inaugurados en Córdoba (1918), sino una revolución universitaria que implicaba la participación estudiantil en la lucha de clases al lado de los oprimidos. Esas tesis fueron corroboradas en el proceso de unidad, afirmando la generalización de la tesis de revolución universitaria, pero sin una estructura que coordinara, aglutinara y organizara al movimiento estudiantil. ${ }^{36}$

Las conclusiones eran producto de la sistematización del movimiento estudiantil iniciado en abril de 1966. Dicha coyuntura fue una compleja mezcla entre la disputa de las expresiones universitarias del Partido Revolucionario Institucional (PRI) y el legítimo descontento estudiantil por la imposición de exámenes de ingreso, autoritarismo de los funcionarios y hostigamiento por parte de los cuerpos de vigilancia universitaria. Se consideraba que dicho movimiento había estallado de modo espontáneo por los hechos inmediatos, pero se alimentaba de causas profundas, levantando demandas populares y propias, aunque de un modo inconexo y desarticulado. Entre las nuevas formas de organización surgidas reconocía de modo especial los Comités de Huelga, comisiones y brigadas de agitación que superaron a las Sociedades de Alumnos, así como nuevos dirigentes y métodos de lucha. Sin embargo, había expresado un proceso autodefensivo, sin capacidad de organizar una ofensiva y sin una perspectiva estratégica, lo que había llevado a un repliegue. Ello señalaba la necesidad de una dirección estable, limitada por el carácter transitorio del estudiante universitario, por lo que se precisaba una organización permanente que no fuese meramente estudiantil, sino política. ${ }^{37}$

Así, la iniciativa política inmediata de la LCE en el sector estudiantil. A fines de 1966 la LCE creó el Movimiento de Izquierda Revolucionaria Estudiantil (MIRE) como estructura que le permitió impulsar una alternativa a la CNED y disputar la dirección al PCM con la Unión Nacional de Estudiantes Revolucionarios (UNER). Desarrolló influencia en centros educativos capitalinos en la UNAM, el Instituto Politécnico Nacional (IPN), la Escuela Nacional de Maestros (ENM) y la Escuela Normal Superior (ENS), pero también en otros estados del país en Escuelas Normales Rurales, en la Universidad de Chapingo, en algunas escuelas en Oaxaca, Veracruz, Ciudad Juárez, Chihuahua, Sonora y Monterrey,

\footnotetext{
36 Liga Comunista por la Construcción del Partido Revolucionario del Proletariado, Liga Leninista Espartaco, Reforma o Revolución universitaria, $2^{a}$ ed., México, 15 de abril de 1966 [1964].

${ }^{37}$ Liga Leninista Espartaco y Liga Comunista por la Construcción del Partido Revolucionario del Proletariado, El movimiento estudiantily la lucha de clases. La selección clasista de la educación burguesa en México, México, 8 de agosto de 1966.
} 
Nuevo León. ${ }^{38}$ La relación con el magisterio vinculó a la LCE directamente a una arista del mundo laboral, pues antes de terminar sus estudios los normalistas comenzaban a desempeñar como docentes sindicalizados. ${ }^{39}$

Lo anterior no implicó que la inserción entre los trabajadores dependiera del sector estudiantil. Los organismos que confluyeron en la LCE habían desarrollado trabajo y posicionamiento político entre los trabajadores para construir independencia política e ideológica. En agosto de 1965 la LCCPRP y la UROC, a propósito de la expulsión de Ortega Arenas del FOCM, denunciaron su política caudillista y el control personal impuesta al movimiento obrero con la asesoría legal, la que obstaculizaba el desarrollo de una dirección colectiva y la independencia de clase. La expulsión de Ortega no significaba el fin de su política, pues pronto había formado el PMT. ${ }^{40}$ También, a propósito de la revisión del contrato del Sindicato Mexicano de Electricistas (SME), la LCE realizó propaganda con el documento "La derrota de los electricistas" en el que planteaba los límites de su lucha económica y propugnaba por plantear la lucha política más amplia. ${ }^{41}$

Si bien el movimiento estudiantil no fue el origen de la inserción de la LCE entre los trabajadores, sí catalizó su trabajo político en el sector. Militantes como Mario Rechy y Fabio Barbosa, en proceso de formación política en 1966, además de estudiar la historia de México, los partidos políticos y el movimiento obrero, asimilaban la legislación relacionada con el mundo del trabajo para comenzar articularse con los trabajadores en las zonas industriales del Estado de México y sectores estratégicos como la energía eléctrica, el petróleo y los ferrocarriles. No es casual que en esos sectores la LCE promoviera la utilización de la coyuntura electoral un año más tarde.

La LCE reconocía el uso de todas las formas de lucha y no descartaba las elecciones. Consideraba que el abstencionismo electoral sólo era viable en tanto existía una fuerza política tal que podía tener un efecto determinante. Entre tanto, se debía participar en todas la coyunturas, entre ellas la electoral, garantizando la independencia del proletariado. ${ }^{42}$ En 1967 se vinculó con otras fuerzas para el efecto: el MLN de Heberto Castillo y el Partido Popular Socialista Revolucionario (PPSR) de Rafael Estrada Villa, para apoyar la candidatura de Demetrio Vallejo en un distrito electoral. No obstante, por órdenes del Secretario de Gobernación, la Comisión Federal Electoral negó el registro a los candidatos del PPSR. ${ }^{43}$ Pese a ello en mayo de 1967 la LCE desarrolló una campaña para plantear la formación de un programa democrático para organizar el descontento popular. ${ }^{44}$

La exacerbación del autoritarismo de Estado y la represión locales, así como acontecimientos de carácter internacional pusieron sobre la mesa la lucha armada. La detención de militantes del POR-t en abril de 1966 llevó a la LCE a pronunciarse meses más tarde al respecto, pese a las diferencias, como una expresión más del carácter represivo y antipopular del Estado. ${ }^{45} \mathrm{El} 12$ de agosto de ese año la policía allanó las escuelas de cuadros Hidalgo y Morelos del MRP en la ciudad de México. El MRP era resultado de un proceso de organización de una fuerza política a fines de 1964 luego del desmantelamiento del

38 FEMOSOP, op. cit., pp. 437.

39 Amador Velasco Tobón. Ciudad de México, 20 de julio de 2017. Realizada por J. Rodrigo Moreno Elizondo.

40 LCCPRP-UROC, Declaración Conjunta. Derrota de la política oportunista de Ortega Arenas, México, $2^{\mathrm{a}}$ ed., 1966 [agosto de 1965], en AGN/ DIPS, C. 1573-B Exp. s/n .

41 “Actividades de la Liga Comunista Espartaco", El Militante, Año 1, núm. 2, septiembre, 1966, p. 21.

42 "Respuesta al Partido Comunista Mexicano. Contra el revisionismo en México”, suplemento de El Militante, Año 1, núm. 2, septiembre, 1966, p. 9.

43 FEMOSOP, op. cit., pp. 436-437. La LCE reconocía la existencia de una Corriente Revolucionaria dentro del PPS que planteaba la identidad de intereses de la burguesía mexicana con la monopolista e imperialista, de lo que se derivaba la clausura de cualquier alianza con dicho sector, así como de la paulatina toma de consciencia de la necesidad de debatir la realidad histórica de un organismo político dirigente del proletariado. "La lucha interna en el PPS", El Militante, Año 1, núm. 2, septiembre, 1966, pp. $22-25$.

44“A la opinión pública de la clase obrera", 19 de mayo de 1967. AGN/ DIPS, c. 512 v. 495, e. 3

45 "Protesta por la agresión burguesa al POR ( $\mathrm{t}$ ) y crítica de la posiciones pequeño-burguesas del trotskismo", El Militante, Año 1, núm. 2, septiembre, 1966, pp. 10-13. 
MLN, antes del inicio de la campaña, en la que participaron ex militantes del Frente Electoral del Pueblo (FEP) -que postuló a Ramón Danzós Palomino-, así como profesores normalistas, ferrocarrileros y petroleros cuya experiencia databa de fines de la década de 1950. En el operativo fueron detenidas aproximadamente 50 personas, incomunicadas por varios días, para luego ser procesadas por delitos como incitación a la violencia, acopio de armas y conspiración. Entre las muestras de solidaridad se encontraron organizaciones estudiantiles, en las que había expresiones de la LCE. ${ }^{46}$ El 29 de septiembre se realizó un mitin en la Escuela de Economía de la UNAM a favor de la liberación de los presos políticos en el que se leyó una carta de Víctor Rico Galán a nombre del MRP, ${ }^{47}$ con la participación del MLN, la Corriente Revolucionaria del PPS y la LCE. Ésta última, en un artículo se pronunció al respecto, que pese a las diferencias políticas, ${ }^{48}$ planteaba no sólo la construcción del partido al calor de la lucha revolucionara, sino la de la vía armada en los siguientes términos:

La LCE y el movimiento revolucionario en México tienen que reivindicar a la violencia proletaria como única forma de lucha que puede enfrentar y destruir el aparato de la violencia burguesa; la violencia revolucionaria no se justifica por su forma sino por su contenido y debe ser, por lo tanto, una violencia consciente, una violencia organizada, una violencia ejercida por las masas y enfocada a los objetivos históricos del proletariado. Debemos educar a las masas en la necesidad de la revolución violenta, denunciando las patrañas de los oportunistas que pregonan la revolución pacífica; pero debemos ante todo educarlas en el socialismo, o sea en el programa y contenido de la revolución..$^{49}$

De tal modo, la LCE comenzó a debatir con seriedad la implementación de la lucha armada como parte del horizonte estratégico. En 1967 se comenzaron a discutir en las células y círculos de formación política la lucha armada, la guerra revolucionaria, la relación entre partido y brazo armado, así como la guerra de guerrillas. De tal modo, el IV pleno del Comité Central de dicho año llegó a la conclusión de que el tránsito al socialismo en México no sería pacífico, pero no por ello abandonó el objetivo de la construcción del partido ni los momentos tácticos previamente establecidos. Luego de eso, sabemos que en la célula Carlos Farías -infiltrada por la DFS- de la que Plutarco Emilio García Jiménez era responsable y en la que participaban los profesores José Tobón, Horacio Guerrero, Pablo Jiménez, Antonio Martínez y Antonio García Jiménez, además de analizar la historia desarrollo del capitalismo, de los partidos y organizaciones de izquierda en México, discutía la importancia de la lucha armada, la estrategia y táctica mediante la creación de un partido que apoyase el proceso revolucionario. En lo inmediato no se iniciaron acciones armadas, pues se planteaba la necesidad de fortalecer la organización y la disciplina creando Comités de Solidaridad para denunciar la agresión de la burguesía contra el pueblo; a la par de una ofensiva con la formación de Círculos Socialistas Clandestinos en todos los sectores y lugares -barrios, escuelas, centros de trabajo-..$^{50}$

\footnotetext{
46 Tales agrupaciones fueron la Alianza de Izquierda Revolucionaria de Economía (UNAM), Brecha Estudiantil (Normal Superior), Comité Pro-Reforma Universitaria (Medicina, UNAM), Estudio y Lucha (Normal de Maestros), Fracción Estudiantil del Partido Obrero Revolucionario, Frente Revolucionario de Acción Democrática (Ciencias Políticas, UNAM), Grupo Miguel Hernández (Filosofía, UNAM), Grupo Progresista de Ingeniería (UNAM), Grupo Revolución (Escuela Nacional Preparatoria), Grupo Rubén Jaramillo (Escuela Nacional Preparatoria 3), Liga Obrera Estudiantil (Ciencias Políticas y Sociales, UNAM), Partido Estudiantil Socialista de Economía (UNAM), Partido Estudiantil Socialista Revolucionario (Ciencias Políticas, UNAM), Unión de Lucha Estudiantil de Ciencias (UNAM). Raúl Ugalde Álvarez, "La guerra sucia. Aquél 12 de agosto...", La Jornada semanal, núm. 415, 16 de febrero del 2003. En http://www.jornada.com.mx/2003/02/16/sem-ugalde.html

47 "Carta de Víctor Rico Galán”, cárcel preventiva del D. F., 29 de septiembre de 1966, en El Militante, Año 1, núm. 2, septiembre, 1966, p. 21.

48 “Acerca de las posiciones del MRP”, El Militante, Año 1, núm. 3, diciembre, 1966, pp. 20-21.

${ }_{49}$ Carlos Méndez, “¡Libertad a Rico Galán, Ugalde y demás detenidos! Nuevas víctimas de la represión burguesa”, El Militante, Año 1, núm. 2, septiembre, 1966, pp. 5-6. La cita es de la última.

${ }^{50}$ Informe Investigaciones Políticas y Sociales, 23 de agosto de 1967, 3 p. AGN/DIPS, c. 516 v. 499 e. 3.
} 
De hecho, aunque la LCE tenía simpatías con otras organizaciones que devendrían parte de la lucha armada, no existían lazos orgánicos. A principios de abril de 1967 la Comisión Política de la LCE, en el documento La Fuga de Genaro Vázquez. Aliento a la Lucha en Guerrero, denunció el terrorismo y la violencia estatal contra los campesinos, obligados entonces por las condiciones de la lucha de clases a la rebeldía violenta y el uso de las armas para rescatar a Genaro Vázquez. Dicha violencia estatal no se ejercía sólo en Guerrero, sino en todo el país, por lo que llamaba a solidarizarse con el pueblo guerrerense y sus dirigentes a través de mítines, propaganda y pintas. Pese a ello, Vázquez, en los Lineamientos programáticos de la Asociación Cívica Guerrerense (ACG) de agosto de 1967, veía en la LCE una desviación del PCM constituida por un núcleo de intelectuales que "priorizan la formación del partido proletario, por lo que desarrollan su principal actividad al seno de los obreros, lo cual los aísla de la lucha política de las grandes masas y formación del partido de vanguardia". ${ }^{51}$ Si bien la LCE no tenía gran un desarrollo técnico militar, denunció en ese año la represión no sólo en Guerrero, sino en Yucatán, Sonora y el Distrito Federal, cuestionando el carácter democrático del gobierno. ${ }^{52}$

Dos acontecimientos parecen haber provocado prematuras acciones armadas. Por un lado, la detención de Daniel Camejo Guanche, Enrique Moreno, Pablo Alvarado y Adán Nieto Castillo, abogado defensor de los militantes del MRP, así como de trabajadores petroleros en agosto de 1967.53 Por el otro, el asesinato de Ernesto "Ché" Guevara en octubre en Bolivia. En tanto la LCE no estaba en condiciones de impulsar un proceso armado amplio, algunos militantes consideraron que una manera de rendirle homenaje y de protestar era mediante bombas contra sus asesinos. Entonces se instaló una bomba en la embajada de Bolivia en México, la cual explotó luego de ser recogida en los laboratorios de la policía. Las investigaciones y persecución llevaron a la detención un mes más tarde de varios militantes: Antonio Geherson, Enrique Condes Lara (preparatoria 8), Luis Enrique Gerardo del Toro y Nájera (preparatoria 7) y Mario Rechy Montiel (preparatoria 7). Estos militantes fueron desconectados de la vida orgánica de la LCE, atestiguaron el ingreso de más presos políticos en los meses siguientes y del movimiento estudiantil-popular de 1968 y consiguieron la libertad hasta 1973, como en el caso de Rechy. ${ }^{54}$ El suceso muestra una inquietud latente en la LCE, pero también que dicha posición no era generalizada, pues las discusiones sobre la táctica y las mediaciones políticas estuvieron presentes en diversos momentos. De hecho, fruto de las discrepancias, en la primera mitad de 1968 algunos militantes, como Yolanda Casas Quirós, rompieron con la LCE y se incorporaron a la lucha armada en el Comando Armado Lacandones, luego parte del núcleo fundador de la Liga Comunista 23 de Septiembre en 1972.55

Aparte de este suceso, hasta donde la evidencia permite afirmar, la lucha armada estuvo supeditada a valoraciones políticas y al momento táctico planteado en el análisis de la situación nacional. De hecho, su posición quedó patente en un artículo que analizaba las rupturas al seno del PPS, en el cual contestaba a las acusaciones de apoyar la guerrilla en todo momento. Así, la LCE respondía:

\footnotetext{
51 Alberto G. López Limón, ¡Comandante Genaro Vázquez Rojas: presente!, ACNR, 2012, pp. 67-68.

52 Célula Cananea, "A los trabajadores, al pueblo en general", 1967, AGN/DIPS, C. 2940-A E. s/n.

${ }^{53}$ Entre ellos Augusto Danglada Ríoz, Pablo Ramírez Salazar, Ramón Sánchez Maza, Alberto Cárdenas Pérez, el abogado Mario Pérez Marín, Ugalde Álvarez, op. cit.

${ }^{54}$ En 1967 ingresaron a prisión José Luis Calva y Juan Ortega Arenas, de la Unidad Obrera Independiente (UOI). FEMOSOP, op. cit., p. 438; Ugalde Álvarez, op. cit.; Mario Rechy Montiel, Del socialismo de estado al capitalismo burocrático. Una sintesis histórica de China y Rusia, México, el autor, 2016, pp. 62-63.

55 Ruiz, op. cit., p. 363; Guadalupe Santiago Quijada y Jorge Balderas Domínguez, "Fundamento ideológico de la acción revolucionaria del grupo armado Lacandones", Nóesis. Revista de Ciencias Sociales y Humanidades, vol. 17, núm. 34, agosto-diciembre, 2008, p. 73; Pedro Echeverría, "La Liga Comunista 23 de Septiembre, la guerrilla urbana más importante de México", Aporrea, 26 de septiembre de 2009, en https://www.aporrea.org/internacionales/a87208.html; Núñez, op. cit., p. 147; Laura Castellanos no reconoce directamente a miembros de la LCE en la fundación de la Liga Comunista 23 de Septiembre. Es probable que muchos se hayan incorporando previamente a otras organizaciones como en el caso señalado: México armado, 1943-1981, México, Era, 2007, p. 207. Rodríguez Araujo asegura que quienes se incorporaron a diversas organizaciones armadas provenían del MIRE: Las izquierdas en México, p. 39.
} 
Hacernos a la ilusión de un tránsito pacífico en los momentos mismos en que la burguesía desata una ola represiva contra los movimientos populares y las organizaciones revolucionarias, es engañar a las masas y entregarlas atadas de pies y manos a la represión burguesa. Sin embargo, esto no quiere decir que seamos partidarios de las guerrillas 'ahora y en todas partes'. [...] La guerra de guerrillas es un método de acción que las masas utilizan en determinadas circunstancias revolucionarias. Este método ha probado su efectividad dentro de condiciones específicas en las revolución china y cubana. [...] Pero de ningún modo somos partidarios de absolutizarlo y de trasladarlo mecánicamente a toda situación revolucionaria." ${ }^{56}$

En ese sentido, el mayor desarrollo político se daba a nivel estudiantil. El ascenso del movimiento estudiantil de 1966 en la UNAM incentivó el crecimiento político en el sector, bajo nuevas formas organizativas e iniciativas. Los organismos que confluyeron en la LCE tenían presencia en las universidades a través de grupos culturales bajo distintos nombres y a fines de 1966 por medio del MIRE y la UNER buscó darles un organismo mayor. La activación política estudiantil decantó en un fuerte impulso de lucha por los espacios de participación tradicionales que constituían las Sociedades de Alumnos hasta su cuestionamiento como formas de representación. Ejemplo de ello fue la disolución de la sociedad de alumnos de la Facultad de Filosofía y Letras (FFyL) en mayo de 1966 y su sustitución por un Comité de Lucha Pro Reforma Universitaria. El grupo creado en 1965 que dio lugar a dicho Comité se llamaba Miguel Hernández..$^{57}$ En octubre de 1966 cuando se restauró la sociedad de alumnos, el grupo aludido ganó las elecciones para la mesa directiva de un periodo anual. Para 1967 alcanzó un centenar de militantes de la LCE, aunque también había de la LOM, bajo la promoción de la discusión y la formación política. Las distinciones entre las labores intelectuales y activistas, así como la penetración del rock y la contracultura, generaron tensiones que fracturaron al grupo en la segunda mitad del año. Para septiembre, los “intelectuales" crearon el grupo José Carlos Mariátegui con 25 militantes de la LCE, mientras que los sesenta restantes conservaron el nombre anterior. Pese a la división se aliaron en la Planilla Negra para contender con éxito de nueva cuenta por la mesa directiva de la sociedad de alumnos de la FFyL de dicho año. ${ }^{58}$

Dicho grupo dio una salida política a la demanda de acceso a la universidad que databa de la década de los cincuenta. La llegada de Ignacio Chávez a la rectoría de la universidad había significado la exclusión de miles de jóvenes mediante la implementación de un examen de admisión como mecanismo excluyente. De ahí que fuera una de las reivindicaciones más importantes junto con la democratización de la universidad. Tras la renuncia de Chávez, producto del movimiento estudiantil, y la designación de Javier Barros Sierra en mayo de 1966, el cumplimiento de los puntos del pliego petitorio logró acabar con esos mecanismos excluyentes estableciendo el pase automático desde la Escuela Nacional Preparatoria.

Ello no solucionaba por completo el problema de los rechazados. Mediante un vano legal Barros Sierra sólo había eliminado el filtro hacia el nivel superior bajo el argumento que la normativa hacía el señalamiento para el primer ingreso y, por tanto, al no tener esa condición los egresados de las preparatorias no tenían por qué ser examinados. Se mantuvieron el examen para ingresar a bachillerato y el sistema incorporado. Así, a fines de 1967 los grupos Miguel Hernández y José Carlos Mariátegui se articularon con las demandas de los rechazados para exigir su ingreso. El proceso se desarrolló rápidamente desde esta última reivindicación o una nueva aplicación del examen, ante la negativa de las autoridades de la UNAM que sólo accedieron a medias becas en escuelas incorporadas. Aunque se aceptó la oferta, continuaron las movilizaciones, añadiendo la exigencia de creación de una nueva preparatoria sumada a las nueve existentes.

56 “La lucha interna en el PPS”, El Militante, Año 1, núm. 2, septiembre, 1966, p. 25.

57 Nombre tomado del poeta español republicano encarcelado por la dictadura de Francisco Franco.

${ }^{58}$ Rivas, op. cit., pp. 262-266, 269-274 
Tras una asamblea junto al entonces auditorio Justo Sierra, se acordó la creación de una preparatoria popular que formara sujetos críticos partícipes de las transformaciones sociales junto al pueblo. No estaba resuelta la ubicación, pero se indagaron los salones desocupados de la facultad, se convocó a los rechazados a inscribirse y a profesores a participar voluntariamente. Bajo un pliego petitorio que exigía el reconocimiento de la preparatoria, financiamiento, un edificio para albergarla y validación del servicio social de estudiantes que formaran parte de la planta docente, la preparatoria popular comenzó cursos en febrero de 1968 con 1500 alumnos inscritos. A lo largo del año mantuvo la lucha por sus reivindicaciones mediante movilizaciones, articuló una organización interna en Comités de Lucha e impulsó la autogestión académica y obtuvo el reconocimiento por parte de la UNAM y la asignación de un local, del cual tomaron posesión después del movimiento estudiantil-popular de 1968.59

\section{Crisis y fragmentación: el movimiento estudiantil-popular de 1968 y una línea de masas}

El movimiento estudiantil-popular de 1968 sacudió al conjunto de las organizaciones políticas de izquierda, acelerando el proceso de reconfiguración de la última década. ${ }^{60} \mathrm{La}$ LCE no fue ajena a dicho proceso, pues participó a través de su estructura estudiantil, así como también de otros sectores en los que tenía influencia, subordinándose a la lógica de participación, representación y dirección de la que se dotó el movimiento. Sin embargo, el proceso atizó las tensiones y tendencias preexistentes, las que se tornaron irresolubles hasta decantar en la crisis orgánica y fragmentación del organismo político.

La participación de la LCE no ha sido analizada con detenimiento, por lo cual se ha generado una imagen de nula incidencia y marginalidad política. En la manifestación del 26 de julio la DFS sólo identificó a Antonio Morín como parte de la LCE y adjudicó militancia en dicho organismo a Roberto Escudero y Luis González de Alba, aunque conoció con posteridad de la participación por documentos a los que tuvo acceso por haber infiltrado la estructura. ${ }^{61} \mathrm{Un}$ enfoque centrado en las movilizaciones diluiría su participación, como en el caso de Núñez, quien planteó que la LCE estuvo fuera del movimiento por considerarlo pequeño-burgués, lo que la habría restringido a la propaganda, pero sin incidencia real -donde, dicho sea de paso, habría que definir los criterios para caracterizar dicha incidencia-. ${ }^{62}$ Por otra parte, el informe de la FEMOSOP señala que, al igual que las JC se alejaron del PCM, los jóvenes en el MIRE se distanciaron por haber sido despreciados. Según este argumento la LCE no habría participado orgánicamente en el movimiento, sino a nivel personal con una participación destacada en sus escuelas. ${ }^{63}$

Lo cierto es que la LCE se subordinó a la lógica del movimiento estudiantil-popular. Se sabe que algunos fungieron como delegados al Consejo Nacional de Huelga $(\mathrm{CNH}) .{ }^{64}$ Además hubo participación de varios militantes en Comités de Lucha, asambleas de base y brigadas, de cuya composición detallada no existe un registro, por lo cual a partir de testimonios se ha recuperado su aportación cualitativa en términos de experiencia política. ${ }^{65}$ Como lo dejan saber documentos de Arturo Vélez, miembro del Comité Central de la LCE y de la célula Sierra Maestra, los militantes participaron en la formación de los Comités de Lucha bajo la perspectiva de promover la ampliación de la conciencia crítica frente al Estado y la extensión de las formas de lucha adoptadas a fin de garantizar el triunfo del proceso. Se secundó el

59 Carlos Muñoz López, 'La Preparatoria Popular 'Mártires de Tlatelolco’ A. C. Orígenes y desarrollo y desincorporación de la UNAM", México, Universidad Pedagógica Nacional, Tesis, 2012, pp. 10-18.

${ }^{60}$ Moreno, op. cit. Aquí recupero algunas reflexiones sobre la LCE adelantadas en ese artículo.

${ }^{61}$ FEMOSOP, op. cit., pp. 67; Jardón, El espionaje..., p. 23. Luis Gonzáles de Alba apenas era un simpatizante de la LCE.

${ }^{62}$ Núñez, op. cit., pp. 85-92.

${ }^{63}$ FEMOSOP, op. cit., p. 436.

${ }^{64}$ Jardón, 1968. El fuego..., pp. 23, 189, 297-300; El espionaje..., pp. 179-185.

${ }^{65}$ Jardón, 1968. El fuego.... 
paro activo, la formación de brigadas y respaldó la iniciativa del movimiento, defendiendo el pliego petitorio y la necesidad de extenderlo a otros sectores.

La ocupación de Ciudad Universitaria (CU) por el Ejército en septiembre de 1968 fue un momento de inflexión. La dirección de la LCE publicó a fines de mes dos documentos: la "Circular a todas las Brigadas Políticas Estudiantiles" y el "Manifiesto número 14", de los cuales conocemos por el documento de Vélez. En ellos se exhortaba a las brigadas de perfil político a hacer propaganda y las de "carácter técnico" a confrontar a la policía cuando las condiciones lo permitiesen. Esto último partía de las prácticas de autodefensa en las escuelas de los primeros días del proceso. La salida del Ejército de CU fue considerada un triunfo político en tanto que acciones como la quema de camiones tras la represión en Tlatelolco el 2 de octubre se interpretaron como formas legítimas de autodefensa. La LCE que había planteado su apoyo al movimiento y cuando se plantearon posiciones de enfrentamiento armado en las asambleas, sus militantes no las pusieron a discusión bajo una orientación de la dirección de la LCE, sino a partir de su criterio. ${ }^{66}$

El movimiento estudiantil puso a prueba el funcionamiento orgánico de la estructura en ese sector de la LCE. Como sugiere el documento de Vélez, más allá de la política de apoyo, los estudiantes debieron resolver situaciones específicas de acuerdo con las circunstancias y dinámica del $\mathrm{CNH} .{ }^{67}$ Después del 2 de octubre, con el movimiento golpeado, el CNH debilitado y sostenido por militantes, las posiciones se dividieron: la mayoría se oponía a la propuesta de jóvenes de la JCM de levantar la huelga, planteando la continuidad del movimiento; la otra parte planteaba combatir las posiciones proclives a la lucha armada, reorganizar el movimiento, extendiéndolo a los obreros por medio de la denuncia de la represión y de la falta de libertades políticas. ${ }^{68}$

Como parte de la extensión y reanimación del movimiento, la Sección Magisterial de la LCE con presencia en la Escuela Normal Superior y en la Nacional de Maestros impulsó un paro laboral bajo la perspectiva de tomar la batuta, por lo cual además convocaba a la formación de asambleas populares. En el contexto de la discusión respecto del levantamiento de la huelga, la convocatoria para el 12 de noviembre hizo esperar al $\mathrm{CNH}$ para resolver hasta conocer los efectos del acontecimiento, y el resultado de las asambleas ferrocarrileras y populares convocadas por los maestros. El paro se realizó con la participación de 750 escuelas y 14 mil maestros, de acuerdo con los Comités Coordinadores de Lucha Magisterial. La respuesta de la Secretaría de Educación Pública (SEP) fue el cese de 63 dirigentes y descuentos salariales a tres mil docentes. Se clausuró la posibilidad de reanimar el movimiento estudiantil y lo que sobrevino fue el levantamiento de la huelga, la disolución del CNH y la lucha por la liberación de los presos políticos. ${ }^{69} \mathrm{La}$ represión de los días finales de 1968 se extendió a la LCE a propósito de la explosión de petardos en las inmediaciones de los edificios del PRI y la Confederación de Trabajadores de México (CTM), pues fueron detenidos y encarcelados militantes de Comités de Lucha de electricistas, petroleros y del magisterio. ${ }^{70}$

En la LCE se acentuaron los cuestionamientos y las tensiones entre tendencias. Por una parte, se encontraba la formación teórica de los cuadros provenientes de la LLE y la LCPRP con algún grado de articulación social entre estudiantes y maestros. Por otra, la inclinación de los cuadros provenientes de la UROC con experiencia de trabajo de base e inserción social, pero con poca participación de la construcción partidaria, lo que se acentuó con la existencia de una relación más distante. También la pulsión por la lucha armada expresada en la instalación de una bomba como protesta por la muerte del

\footnotetext{
66 Arturo Vélez, Daniel Arroyo y Héctor Martínez, "Nuestros reformistas avanzan firmemente por la ruta del culto a la espontaneidad”, México, 7 de octubre de 1968; Arturo Vélez, “¿Qué pasa con nuestros dirigentes que no dirigen a la Liga?”, México, 14 de octubre de 1968.

${ }^{67}$ Jardón, 1968. El fuego..., p. 23

68 Vélez, op. cit.; Vélez, Arroyo y Martínez, op. cit.

${ }^{69}$ Jardón, 1968. El fuego..., pp. 120, 268-270.

${ }^{70}$ Fernández sólo menciona la detención sin referir nombres. op. cit., pp. 157-158.
} 
Che por parte de los cuadros estudiantiles. Las disputas expresaron las tensiones y limitaciones de construcción orgánica en términos de formación política, homogenización y homologación política, construcción de acuerdos, funcionamiento de espacios orgánicos internos e implementación de una perspectiva estratégica y táctica.

La lucha interna hasta la fragmentación tuvo cuatro polos. Primero, la que reivindicaba construcción de un partido revolucionario con los elementos dispersos, la formulación de una perspectiva estratégica y táctica sin una relación social orgánica, así como la formulación de un programa. Segundo, el desarrollo orgánico y técnico político-militar para la lucha armada. Tercero, la exigencia de vinculación orgánica con el pueblo sus demandas aportando dirigentes para la revolución proletaria y el futuro partido revolucionario. Finalmente, se planteaba armonizar la construcción teórica y programática con la lucha de masas e inserción social. En suma, cohabitaban tendencias que podríamos caracterizar como: teórica autorreferencial y sin práctica, militarista, societal y sociopolítica. En el proceso se fortaleció la posición societal en el preludio de la Primera Asamblea Nacional de la LCE a celebrarse en 1969 con la perspectiva de realizar un balance del panorama la lucha de clases en México, así como en el periodo que anunciaba la insurgencia sindical de la primera mitad de la década de 1970.

En diciembre de 1968, ante el desenlace del movimiento estudiantil-popular, se acentuaron los cuestionamientos a la dirección de la LCE y de su papel como vanguardia. Una parte del Comité Central preveía el incremento de las luchas populares contra el Estado y publicó el documento Notas para una línea de masas actual. Algunas experiencias del movimiento estudiantil. Bajo el panorama de la represión, limitación de libertades políticas y el agotamiento de la democracia burguesa, el documento extraía aprendizajes del movimiento bajo el prisma de la matriz sociopolítica maoísta, reconociendo las experiencias de vinculación con el pueblo. La seccional Magisterial criticó el intelectualismo y lo que consideraba actitudes autoritarias y pedantería de la dirección frente a la base considerada atrasada, a la vez que expresaba su acomplejamiento por incapacidad de discutir tesis políticas o filosóficas, a lo que atribuía la pérdida de simpatía entre el magisterio, lo que le impedía convertirse en dirección.

Del mismo modo, entre la base militante y las células se publicó el documento Una nueva revolución, en el que se realizaba una crítica al trabajo intelectual tanto como el trabajo reducido a los obreros y a la lucha ideológica. Por el contrario, se planteaba la necesidad de incorporar a otros sectores y asumir el pensamiento de Mao Tse Tung. Ello implicaba apoyarse en las masas y sus luchas inmediatas ligándolas a luchas políticas contra el Estado. Al realizarse la convocatoria para la Primera Asamblea Nacional de la LCE para 1969, la Célula Sierra Maestra criticó que se destinara a analizar la lucha de clases en México en lugar de discutir los problemas orgánicos internos. El abanico de posiciones críticas se fortaleció a partir de la interpretación del papel de la LCE a propósito de la movilización del $1^{\circ}$ de mayo de 1969 en la que la Seccional 28 de Marzo acusaba de nueva cuenta la marginalidad. ${ }^{71}$

En los hechos se fortaleció la posición de vinculación práctica y material en contraposición a otras tareas políticas. Luego de una serie de reuniones y discusiones a mediados de 1969 surgió una nueva estructura dentro de la LCE llamada Seccional Ho Chi Minh, crítica de la teorización, la construcción del partido y del programa. Aglutinó a militantes de las seccionales Magisterial, 28 de Marzo, Estudiantil y una campesina de Morelos y Puebla, del Comité Central y de la Comisión Política. Dicha tendencia se fortaleció entre las bases y la dirección impulsando lo que concebía como un proceso de rectificación mediante un documento con sus planteamientos políticos sobre una línea de masas derivada no de la teoría sino de la práctica, ${ }^{72}$ y el periódico Detonador a partir de noviembre de 1969 , agudizó su crítica y priorizó la puesta en práctica de su perspectiva de articulación en todos los sectores a partir de $1970 .^{73}$ Pese a ello, la dirección de la LCE continuó desarrollando una política propia y a principios de 1971

\footnotetext{
${ }^{71}$ Núñez, op. cit., pp. 92-98.

72 Seccional Ho Chi Minh de la Liga Comunista Espartaco, "Luchemos por una táctica revolucionaria basada en la línea proletaria de masas", México D.F., 25 de octubre de 1969.

73 Núñez, op. cit. pp. 92-110.
} 
impulsó una campaña de capacitación política e ideológica para sus cuadros sobre la caracterización de la sociedad mexicana, el movimiento obrero y revolucionario; la socialización de experiencias sistematizadas e incluso trabajaba en el desarrollo de un proyecto editorial..$^{74}$

Lo cierto es que en la práctica continuó el desarrollo de trabajo político sectorial. Sabemos que el Seccional Magisterial impulsó una política de formación de Comités de Lucha, Comités Coordinadores y de formación de Comités Obreros Populares. ${ }^{75}$ En el seno del movimiento ferrocarrilero la Seccional 28 de Marzo, además de apoyar la lucha que seguía el movimiento estudiantil denunciando la represión y exigiendo la liberación de los presos políticos, impulsó en 1969 la lucha por reivindicaciones de los trabajadores y la democratización del sindicato apropiándose de los clubes promovidos por la dirección sindical corrupta. En agosto de ese año se dio a conocer un boletín que planteaba el "Plan Demetrio Vallejo" que buscaba su reconocimiento como dirigente sindical y líder de la lucha del conjunto del país, ${ }^{76}$ cuyo desarrollo desconocemos. La LCE desarrolló una vinculación especial con la industria textil pues Francisco González realizaba trabajo sindical en Hilos Cadena, en la Merced, ${ }^{77}$ en tanto que la Seccional Ho Chi Minh comenzó a realizar trabajo en la industria de hilados y tejidos Ayotla, publicando junto con Política Popular el periódico Lucha Popular. ${ }^{78}$ Para 1971 se planteaba dentro de la campaña de capacitación política e ideológica la circulación de dos documentos con la sistematización de las experiencias de la LCE en la fábrica Spicer y en una de las preparatorias populares. ${ }^{79}$

Las preparatorias populares mantuvieron una relación con los Comités de Lucha. Luego de 1968 la LCE participó en la conformación de los Comités Coordinadores de los Comités de Lucha (CoCo), creados en 1969 para dar continuidad a las formas de lucha emergidas en 1968, forma flexible de organización que permitía la participación de diversas expresiones políticas. Los CoCo funcionaron hasta la represión del 10 de junio de 1971 como articuladores de la lucha por la liberación de los presos políticos, contra los grupos de choque en la universidad, la solidaridad con procesos locales y globales.$^{80} \mathrm{El}$ Comité de Lucha de Arquitectura en la UNAM desde 1966 catalizaba la participación política y articulaba el trabajo con las preparatorias populares impulsando un mes de servicio social como requisito de ingreso a la UNAM para los alumnos. ${ }^{81}$

También se realizó el trabajo político-militar y relación con organizaciones armadas. Antes de 1968 existía un contacto con Genaro Vázquez por medio de Plutarco Emilio García que se fortaleció con la tendencia de vinculación social. El informe de la FEMOSOP señala que en 1969 LCE comenzó a construir sus redes de abastecimiento y comunicación, así como Comités Revolucionarios Obreros. Una vez creada la Seccional Ho Chi Minh se establecieron relaciones de solidaridad e intercambio de experiencias con la ACNR de Genaro Vázquez Rojas, el PDLP de Lucio Cabañas Barrientos, así como el Movimiento de Acción Revolucionaria (MAR). La liga con Cabañas derivaba de la relación que tenía con Vicente Estrada Vega, quien había estudiado en la Normal Rural Raúl Isidro Burgos, en Ayotzinapa,

\footnotetext{
74 "Circular número 2 de la campaña de capacitación política e ideológica", Boletín interno de la Liga Comunista Espartaco, México, núm. 3, 21 de abril de 1971, pp. 1-2.

75 Seccional Ho Chi Minh, op. cit.

${ }^{76}$ Comité de Lucha por Oficinistas, "A los Comités de Lucha de las distintas especialidades del sistema de ferrocarriles nacionales de México"; 28 de marzo, Seccional Ferrocarrilera, Liga Comunista Espartaco, nueva época, núm. 7, septiembre de 1969, en AGN, DIPS, c. 2325 e. s/n.

77 Carmelo Enríquez Rosado. Entrevista realizada por J. Rodrigo Moreno Elizondo. Cuernavaca, Morelos, México. 10 de agosto de 2017.

78 Núñez, op. cit., pp. 117-128.

79 "Circular número 2 de la campaña de capacitación política e ideológica", Boletín interno de la Liga Comunista Espartaco, México, núm. 3, 21 de abril de 1971, p. 2.

80 Oikión, “Student Organizing"; Rivas, op. cit., pp. 627, 641-642, 646, 662-672.

81 Gaspar Morquecho Escamilla, "A 6,570 días del levantamiento armado del EZLN (XXI) . La tormenta y los remolinos multicolores en la 'mecánica nacional' - III” en América Latina en Movimiento online, Agencia Latinoamericana de Información, 15 de abril de 2012.
} 
Guerrero. La Seccional Ho Chi Minh intercambió militantes y apoyo con el Partido de los Pobres pues comulgaba con la idea de ligarse al pueblo. ${ }^{82}$

Sin embargo, desde 1970 la posición de la LCE sobre la lucha armada se transformó a propósito de la creciente represión y el auge de las movilizaciones populares en el país, en la perspectiva de las elecciones de ese año. Por un lado, las luchas de los metalúrgicos de Monclova, Coahuila, de los trabajadores de Automex y de Ayotla en el Estado de México y diversas fábricas en el Distrito Federal, el movimiento magisterial en Nuevo León y Chihuahua, los cañeros en Atecingo, los campesinos de Puebla, Guerrero y Yucatán, así como el movimiento estudiantil en diversas regiones. ${ }^{83}$ Por otro, se había asesinado al radiotécnico Ramón Campos y detenido a Mario R. Menéndez Rodríguez, Ignacio González, Raymundo López, Ponciano Luna, Demóstenes Onofre y Gabriel Peralta. De tal modo, consideraba necesario enfrentar la represión con una política de masas, pues:

La única garantía que existe, no de detener la represión, pero sí de hacerla ineficaz y poder responder golpe por golpe, es que el movimiento revolucionario desarrolle un trabajo y una política proletaria de masas. Mientras los elementos más politizados y decididos sigan actuando por su cuenta, exhibiendo su radicalidad ante el pueblo por medio de acciones estimulantes o ejemplares, tratando de 'hacer' la revolución para el pueblo, pero no con el pueblo, seguirán cayendo uno a uno irremediablemente, por grande que sea su decisión de lucha y variadas sus medidas de clandestinidad. [...] No se trata, entonces, de perfeccionar la técnica del foco guerrillero o de mejorar los métodos terroristas. Por ese camino sólo se le facilitan las cosas al gobierno y se malgastan fuerzas. El problema consiste en saber fundirse con las masas, en aprender de ellas y en ayudarlas a organizar su lucha, forjando una línea política revolucionaria para las masas, con medidas de clandestinidad y seguridad para el pueblo y basadas en el pueblo. ${ }^{84}$

En ese sentido, aunado a las medidas de clandestinidad implementadas, desconocemos el grado de inserción de los procesos de los que la LCE formó parte, lo que a su vez dificulta sopesar el papel de la represión en su desaparición. Lo que sabemos es que la tensión entre las tendencias no fue resuelta y fue la determinante en su ruptura. El cuestionamiento a la dirección por parte de la Seccional Ho Chi Min desembocó en la disolución entre fines de 1971 y principios de 1972. Los teóricos fueron expulsados y continuaron su actividad intelectual en publicaciones como Cuadernos Revolucionarios o La Causa del Pueblo y proyectos como la Cooperativa de Cine Marginal (1971-1976) en la que se imbricó cine y activismo sindical dando voz a los trabajadores. ${ }^{85}$ La Seccional Flores Magón se transformó en la Organización Comunista Cajeme con su publicación Política Proletaria. ${ }^{86}$ La Seccional Ho Chi Minh continuó bajo el mismo nombre, postergó la construcción teórica, programática y del partido hasta 1973, continuó el trabajo en la ciudad de México, el Estado de México, Morelos, Puebla, Oaxaca y Guerrero, privilegió la inserción social y brindó apoyo a Cabañas y a otras guerrillas hasta la represión de 1974.

En el proceso de descomposición numerosas células de la LCE quedaron desarticuladas y algunas dieron lugar a nuevas agrupaciones que se desarrollaron al calor de la lucha política y de masas en la década de los setenta. El trabajo desarrollado en el movimiento estudiantil y las preparatorias populares se autonomizó, mientras el realizado en Arquitectura y en la Escuela Nacional de Antropología e Historia

82 FEMOSOPP, op. cit., pp. 437-438; Núñez, op. cit. pp. 158-159.

83 Ver "Agitación en ferrocarriles", "Manifestación en Monclova", "Nuevos actos de repudio popular a Echeverría", "Lucha de masas en el campo. Combativo movimiento de los cañeros", "Movimiento Magisterial", "La lucha de los obreros de Automex", "Durango: dos meses de lucha", en El Militante, Año 5, núm. 16, 20 de marzo de 1970.

84 "Presos políticos. La otra cara de las elecciones", El Militante, Año 5, núm. 16, 20 de marzo de 1970, p. 2.

85 Barbosa, op. cit., p. 120; Alonso Getino Lima, "Expectativas y experiencias de un cine marginal (1971-1976)", Secuencia, núm. 101, mayo-agosto, 2018, p. 251.

86 Barbosa, op. cit., p. 120. Otras fuentes señalan que era la Seccional Cajeme que devino en la Liga Comunista Cajeme. No es claro si se trató del mismo organismo. 
(ENAH) se tradujo en la creación de las dos primeras experiencias de autogobierno universitario. ${ }^{87}$ Miembros de células magisteriales, estudiantiles y sindicales formaron el grupo Compañero que dio lugar a la Organización Revolucionaria Compañero (ORC). ${ }^{88} \mathrm{El}$ núcleo de la de la Escuela de Agricultura en Chapingo fundó el Partido de la Clase Obrera Mexicana (PCOM) y editó El Organizador Socialista. ${ }^{89}$ Esas agrupaciones oscilaban entre la construcción de organizaciones de masas antes que el partido o bien la construcción dialéctica de ambas.

\section{A modo de cierre: indicios, tesis e interrogantes}

Esta suma preliminar ha permitido comenzar a dar un panorama más claro sobre la LCE. Hoy día la reconocemos como matriz de importantes experiencias sociales y políticas del último tercio del siglo XX: las preparatorias populares inauguradas en 1968, las experiencias de autogobierno y cogobierno en diversas facultades de la UNAM y en la ENAH, la Cooperativa de Cine Marginal y organismos sociopolíticos en el movimiento urbano popular. No resulta extraordinario pensar que otros de sus cuadros se incorporaron a experiencias que aún sea necesario vincular a tal experiencia política.

Dicha organización logró erigirse como polo de atracción social y política frente al PCM, el POCM y el PPS. En términos formales se podría decir que logró construir una organización política para la articulación con las demandas sociales y conducción política. Sin embargo, no logró erigirse en "cabeza del proletariado" en el sentido que planteaba Revueltas. De tal modo, su disolución terminó con toda posibilidad de cristalización de dicha aspiración que sólo sería posible en el marco de su participación de la lucha de clases y de la lucha política concreta. Paradójicamente, hasta donde sugiere la evidencia existente, pese a haberse desarrollado en un contexto altamente represivo, la lucha política interna y las diferencias no resueltas parecen haber sido las causales de su crisis terminal y dispersión.

En ese sentido, la LCE no logró madurar un proyecto sociopolítico alternativo en la década de los sesenta más allá del horizonte socialista. En gran medida porque comenzaba a penetrar y articularse orgánicamente, aunque incipientemente, en diversos sectores sociales: campesinos, obreros, electricistas, ferrocarrileros y estudiantes. Transitó de estar volcada con intensidad a las actividades de solidaridad con las luchas de la periferia (Cuba, Vietnam y Camboya) a una perspectiva que anudaba la aportación a la transformación mundial desde la trinchera local. Al insertarse en la realidad mexicana el desarrollo de los movimientos estudiantiles tuvo un fuerte impacto en la práctica de la LCE y sus iniciativas políticas. Se profundizó el programa político en términos del conocimiento de la realidad universitaria y de las perspectivas de transformación, pero el proceso de conocimiento del país y de construcción de una alternativa fue más lento. De tal manera que el movimiento estudiantil-popular de 1968 dotó de un contenido político nuevo al conjunto de la izquierda que costó trabajo incorporar o digerir a la LCE: la necesidad de una línea de masas.

El conocimiento de la LCE y su influencia sociopolítica no está agotado. Aún es necesario profundizar en su desarrollo orgánico sectorial y regional: en el sector estudiantil del MIRE y de la UNER para tener un panorama más claro de su influencia, así como de su devenir posterior. Falta explorar con detalle las experiencias de trabajo en las regiones de México entre obreros, electricistas, ferrocarrileros, maestros y campesinos hasta conocer en mayor medida su incidencia y peso específico. Del mismo modo, pese a los elementos recuperados, es necesario profundizar el grado de participación de la guerrilla y de otras formas de lucha como la electoral. Resta también sopesar con mayor profundidad los debates internos, entre ellos los relativos a la primera Asamblea Nacional, así como el papel de la represión sobre

${ }^{87}$ Rafael Robles Gil, Universidad, autogestión y modernidad: estudio comparativo de la formación de arquitectos 1968-1983, México, Centro de Estudios Sobre la Universidad / UNAM, 1988.

${ }_{88}$ Carmelo Enríquez, entrevista citada.

89 Célula Sierra Maestra, 1969; Secretariado, 1977; Núñez, 2012: 91-110, 147; Enríquez, 2017; Hernández, 2018; Barbosa, op. cit., p. 120. 
su disolución. La reconstrucción histórica, la recuperación de documentos en manos de dirigentes y militantes, así como la creación de fuentes por medio de la historia oral brindará mayores luces sobre el organismo político. Es esta una invitación a desarrollar investigaciones orientadas a llenar esos vacíos de conocimiento.

\title{
Fuentes consultadas
}

\author{
Fuentes impresas \\ Hemerografía \\ Brecha Estudiantil \\ Boletin Interno de la Liga Comunista Espartaco \\ El Militante \\ 28 de Marzo
}

\section{Bibliografía}

Anguiano, Arturo, "El espartaquismo en México. Aproximación crítica. Primera contribución a la autocrítica del movimiento revolucionario en México", México, 1968, en Arturo Anguiano, José Revueltas, un rebelde melancólico, México, Pensamiento Crítico, 2017, pp. 273-303.

Entre el pasado y el futuro. La izquierda en México, 1969-1995, México, Universidad Autónoma Metropolitana-Xochimilco, 1997.

Barbosa, Fabio, "La izquierda radical en México", Revista Mexicana de Sociología, México, Universidad Nacional Autónoma de México, vol. 46, núm. 2, abril-junio, 1984, pp. 111-138.

"Las utopías cambiantes", Nexos, 1 de agosto de 1983.

Bennet, Vivienne, "Orígenes del Movimiento Urbano Popular Mexicano: pensamiento político y organizaciones políticas clandestinas, 1960-1980", en Revista Mexicana de Sociología, México, Universidad Nacional Autónoma de México, vol. 55, núm. 3, julio-septiembre, 1993, pp. 89-102.

Camacho de Schmidt, Aurora y Arturo Schmidt, "Translating the Fear. A Mexican Narrative of Militancy, Horror and Redemption”, en Alberto Ulloa Borneman, Surviving Mexico's Dirty War. A political prisioner's memoir, Philadelphia, Temple University Press, 2007, pp. 1-17.

Carr, Barry, La izquierda mexicana a través del siglo XX, México, Era, 1996.

Castellanos, Laura, México Armado, 1943-1981, México, Era, 2007.

Christiansen, Samantha y Zachary A. Scarlett, The Third World in the global 1960's, New York, Berghahn Books, 2013.

De la Garza, Enrique, León T. Ejea y Luis F. Macías, El otro movimiento estudiantil, México, Extemporáneos, 1986.

Estrada, Ulises y Luis Suárez (ed.), Rebelión Tricontinental. Las voces de los condenados de la tierra de África, Asia y América Latina, Tricontinental/ Ocean Sur, 2006.

Fiscalía Especial para Movimientos Sociales y Políticos del Pasado (FEMOSOPP), Informe histórico a la sociedad mexicana, México, sin pie de imprenta, 2006.

Getino Lima, Alonso, "Expectativas y experiencias de un cine marginal (1971-1976)", Secuencia, México, Instituto Mora, núm. 101, mayo-agosto, 2018, pp. 232-255

González Villarreal, Roberto, Historia de la desaparición. Nacimiento de una tecnología represiva. México, Terracota, 2012.

Jardón, Raúl, El espionaje contra el movimiento estudiantil. Los documentos de la Dirección Federal de Seguridady las agencias de inteligencia estadounidense en 1968, México, Ítaca, 2003. , 1968. El fuego de la esperanza. México: Siglo XXI, 1998.

Hernández Navarro, Luis, “Antonio Martínez, el camarada Tomás”, en La Jornada, México, 13 de julio de 2010. 
Herrera Calderón, Fernando, "Working class-heroes: Barrio consciousness, Studen Power and the Mexican Dirty War", en Jaime M. Pensado y Enrique Ochoa (eds.), México beyond 1968. Revolutionaries, radicals and repression during the global sixties and subversive seventies, United States of America, The University of Arizona Press, 2018, pp. 153-174.

Gilly, Adolfo, "Lo que existe no puede ser verdad", New Left Review, núm. 64, julio-agosto, 2010, pp. 3738.

López Limón, Alberto Guillermo, ¡Comandante Genaro Vázquez Rojas: presente!, México, Asociación Cívica Nacional Revolucionaria, 2012.

Moreno Elizondo, J. Rodrigo, "El movimiento estudiantil-popular de 1968 y la recomposición de las organizaciones políticas de izquierda", Revista Mexicana de Ciencias Politicas y Sociales, México, UNAM, Nueva Época, Año LXIII, núm. 234, septiembre-diciembre, 2018, pp. 239-264.

Morquecho Escamilla, Gaspar, "A 6,570 días del levantamiento armado del EZLN (XXI) . La tormenta y los remolinos multicolores en la 'mecánica nacional' - III” en América Latina en Movimiento online, Agencia Latinoamericana de Información, 15 de abril de 2012.

Núñez Membrillo, Hugo, Las organizaciones maoistas de los setentas y su vinculación con las luchas populares: el caso de la Seccional Ho Chi Minh, México, Universidad Nacional Autónoma de México, tesis de licenciatura, 2012.

Oikión Solano, Verónica, "Student Organizing in Post-1968 Mexico City: The Coordinating Comision of Commitees of Struggle and State Violence", en Jaime M. Pensado y Enrique Ochoa (eds.), México beyond 1968. Revolutionaries, radicals and repression during the global sixties and subversive seventies, United States of America, The University of Arizona Press, 2018, pp. 236-253.

Oikión, Verónica, Eduardo Rey Tristán y Martín López Ávalos, El estudio de las luchas revolucionarias en América Latina (1959-1996). Estado de la cuestión, México, El Colegio de Michoacán, 2013.

Ortega, Max y Ana Alicia Solís de Alba, La izquierda mexicana. Una historia inacabada, México, Ítaca, 2012.

Rechy Montiel, Mario, Del socialismo de estado al capitalismo burocrático. Una sintesis histórica de China y Rusia, México, el autor, 2016.

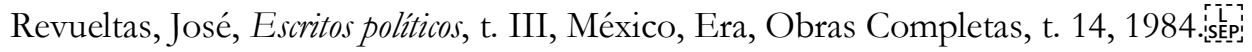

Rivas Ontiveros, René, La izquierda estudiantil en la UNAM. Organizaciones, movilizaciones y liderazgos (19581972), México, Universidad Nacional Autónoma de México-Facultad de Estudios Superiores Aragón/ Miguel Ángel Porrúa, 2007.

Robles Gil, Rafael, Universidad, autogestión y modernidad: estudio comparativo de la formación de arquitectos 19681983, México, Centro de Estudios Sobre la Universidad - UNAM, 1988.

Rodríguez Araujo, Octavio, La izquierda en México, México, Orfila, 2015.

, "Violencia social (un intento conceptual para el México actual)", Este país. Tendencias y opiniones, núm. 76, julio, 1997, pp. 1-10.

Ruiz Mendoza, Florencia, "El Movimiento Estudiantil de 1968išpen el proceso de radicalizacióni la lucha armada en México: 1968-1971", Conflicto Social, Año 4, núm. 5, junio, 2011, pp. 355-373.

Santiago Quijada, Guadalupe y Jorge Balderas Domínguez, "Fundamento ideológico de la acción revolucionaria del grupo armado Lacandones", Nóesis. Revista de Ciencias Sociales y Humanidades, vol. 17, núm. 34, agosto-diciembre, 2008, pp. 66-91.

Torres-Ruiz, René, "Carlos Pereyra: una breve mirada a su vida y obra", Estudios políticos, novena época, Núm. 23, mayo-agosto, 2011, pp. 197-214.

Ugalde Álvarez, Raúl, "La guerra sucia. Aquél 12 de agosto...”, La Jornada semanal, núm. 415, 16 de febrero del 2003. En http://www.jornada.com.mx/2003/02/16/sem-ugalde.html [Consultado el 12 de agosto de 2018]

Ulloa Borneman, Alberto, Surviving Mexico's Dirty War. A political prisioner's memoir, Philadelphia, Temple University Press, 2007. 
Vacah, José Manuel, “Taibo II, de alfabetizador de obreros en Ecatepec a director del FCE”, Tercera vía, 10 de octubre de 2018.

"El origen espartaquista de Taibo II y Armando Bartra, la herencia de José Revueltas", El Revueltas Times, 28 de octubre de 2018.

\section{Fuentes digitales}

Movimientos Armados en México, México, El Colegio de México. En línea en:

http://movimientosarmados.colmex.mx/

\section{Documentos}

Célula Sierra Maestra, "Al Comité Central de la Liga Comunista Espartaco. A todos los militantes de la

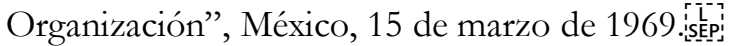

Comité de Lucha por Oficinistas, "A los Comités de Lucha de las distintas especialidades del sistema de ferrocarriles nacionales de México".

Liga Comunista por la Construcción del Partido Revolucionario del Proletariado, Unión Reivindicadora Obrero-Campesina, Declaración Conjunta. Derrota de la política oportunista de Ortega Arenas, México, $2^{a}$ ed., 1966 [1965].

Liga Comunista por la Construcción del Partido Revolucionario del Proletariado, Unión Reivindicadora Obrero-Campesina, Liga Leninista Espartaco, Reforma o Revolución universitaria, $2^{\mathrm{a}}$ ed., México, 15 de abril de 1966 [1964].

La Comisión Política del Comité Central de la Liga Comunista Espartaco al Comité Central del Partido Comunista Mexicano, 3 de julio de 1966.

Seccional Ho Chi Minh de la Liga Comunista Espartaco, "Luchemos por una táctica revolucionaria basada en la línea proletaria de masas", México D.F., 25 de octubre de 1969.

Vélez, Arturo, “¿Qué pasa con nuestros dirigentes que no dirigen a la Liga?” México, 14 de octubre de 1968.

Vélez, Arturo, Daniel Arroyo y Héctor Martínez, "Nuestros reformistas avanzan firmemente por la ruta del culto a la espontaneidad", México, 7 de octubre de 1968.

\section{Entrevistas}

Enríquez Rosado, Carmelo. Cuernavaca, Morelos, México. 10 de agosto de 2017. Realizada por J. Rodrigo Moreno Elizondo.

Velasco Tobón, Amador. Ciudad de México, México. 20 de julio de 2017. Realizada por J. Rodrigo Moreno Elizondo. 